\title{
Rio Carioca, um imaginário nacional: de lenda indígena ao esquecimento
}

DOSSIER RIOS E CIDADES: ARAGUAIA

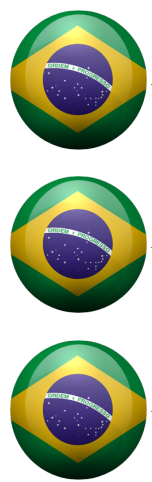

\section{Noemia de Oliveira Figueiredo}

Arquiteta, D.Sc., Prof. Adjunto do Departamento de Arquitetura e Urbanismo, Instituto de Tecnologia da Universidade Federal Rural do Rio de Janeiro. Rio de Janeiro [RJ] Brasil <noemiafigueiredo@gmail.com>.

\section{Luiz Augusto dos Reis Alves}

Arquiteto, D.Sc., Prof. Adjunto do Departamento de Arquitetura e Urbanismo, Instituto de Tecnologia da Universidade Federal Rural do Rio de Janeiro. Rio de Janeiro [RJ] Brasil <luizaugustoalves@gmail.com>.

\section{Mário Saleiro Filho}

Arquiteto, D.Sc., Prof. Adjunto do Departamento de Arquitetura e Urbanismo, Instituto de Tecnologia da Universidade Federal Rural do Rio de Janeiro. Rio de Janeiro [RJ] Brasil <saleirofilho@gmail.com>.

\section{Resumo}

O objetivo principal desse artigo é refletir sobre a relação entre o Rio Carioca, a cidade do Rio de Janeiro e o seu reconhecimento junto à população da cidade em termos de memória e identidade. Para fins de obtenção do objetivo alcançado, iniciamos nossa pesquisa com uma breve explicação sobre o projeto políticopedagógico do ideário nacionalista promovido pela antiga Academia Imperial de Belas Artes do Rio de Janeiro no século XIX. Elegemos como ponto de partida e ao mesmo tempo de "ancoragem" de nossas reflexões, a pintura intitulada "A carioca", um retrato idealizado de cunho identitário nacionalista do Rio Carioca de autoria do artista Pedro Américo. Em seguida, desenvolvemos um breve histórico sobre o Rio Carioca delineando seu trajeto original e mudanças ocorridas ao longo do tempo. Identificamos e elegemos 5 (cinco) lugares em seu percurso, e nestes foram realizadas entrevistas e registro gráfico de modo a verificar o objetivo proposto.

\section{Palavras-chave}

Memória. Identidade. Paisagem Cultural. Rio Carioca.

\section{Carioca River, a national imaginary: from indigenous legend to oblivion}

\begin{abstract}
The main objective of this article is to reflect on the relationship between Rio Carioca, Rio de Janeiro city and its recognition with the population of the city in terms of memory and identity. In order to obtain the achieved goal, we began our research with a brief explanation of the political-pedagogical project of the nationalist ideology promoted by the former Imperial Arts Academy of of Rio de Janeiro in the 19th century. We chose as a starting point and at the same time as "anchoring" of our reflections, the painting titled "A carioca", an idealized portrait of nationalist identity of Rio Carioca authored by the artist Pedro Américo. Next, we develop a brief history about Rio Carioca delineating its original path and changes that have occurred over time. We identified and elected 5 (five) places in their course, and in these interviews and graphic registration were carried out in order to verify the proposed goal.
\end{abstract}

\section{Keywords}

Memory. Identity. Cultural landscape. Carioca River. 


\section{Introdução}

A linha de investigação denominada geografia cultural tem como premissa analisar as intervenções humanas que podem ser identificadas na superfície terrestre, constituindo o conceito de paisagem cultural. A ferramenta adotada para análise da paisagem cultural são os códigos simbólicos que são as pinturas, poesias, músicas, contos populares e outros tipos de manifestações artísticas que podem ser lidas e interpretadas como representações da paisagem que imprimem significados a um lugar (Cosgrove, 1998). Deste modo, esta pesquisa teve como ponto de partida a função da obra pictórica "A Carioca" (1882) do artista Pedro Américo a qual procurou valorizar alegoricamente a identidade do Rio Carioca com a cidade e sua população. Portanto, o objetivo deste artigo é refletir sobre a relação entre o Rio Carioca, a cidade e sua população em termos de identidade e memória, buscando-se verificar se tais aspectos ainda persistem na paisagem da cidade do Rio de Janeiro do século XXI.

A memória é a base para construção da identidade, sendo um elemento que se constitui de lembranças coletivas e individuais que valorizam o indivíduo, um grupo ou uma comunidade que vai ser refletida na auto-estima, ou seja, em uma força social de poder. Em uma sociedade existem muitas memórias coletivas que se fragmentam e se confundem em memória oficial e memória oculta (Freire et al, 2002).

A referência do passado serve para manter a coesão dos grupos e instituições que compõem uma sociedade, para definir seu lugar respectivo, sua complementaridade, mas também as oposições irredutíveis. Manter a coesão interna e defender as fronteiras daquilo que um grupo tem em comum, em que se inclui o território (no caso de Estados), eis as duas funções essenciais da memória comum (Pollak apud Freire et al., 2002, p. 125).

A metodologia elaborada teve como início um breve histórico do Rio Carioca e seu trajeto ao longo dos anos, identificamos e elegemos 5 (cinco) trechos por onde o rio passava, alguns deles ainda há sua permanência física em termos de curso d'água e, outros, não mais, apenas marcos arquitetônicos por onde suas águas corriam. Elaboramos um pequeno histórico e descrição de cada situação atual.

Já nos locais investigados, a pesquisa adotou a entrevista de perguntas estruturadas aos transeuntes. Foram elaboradas previamente 5 (cinco) perguntas, sendo a primeira e a última de respostas abertas e as outras 3 (três) fechadas. A abordagem inicial aos entrevistados foi feita a partir do interesse espontâneo das pessoas nos desenhos de observação que estavam sendo feitos in loco por onde o Rio Carioca passa e passava até os dias de hoje, como o Largo do Boticário (Figura 1), a Praia do Flamengo (Figura 2) (em frente à Rua Barão do Flamengo), Largo da Carioca, ou por onde existem resquícios construtivos do Rio Carioca na paisagem, como nos Arcos da Lapa (Figura 4) e na Praça XV de Novembro (Figura 5) (Mollica¹ sic).
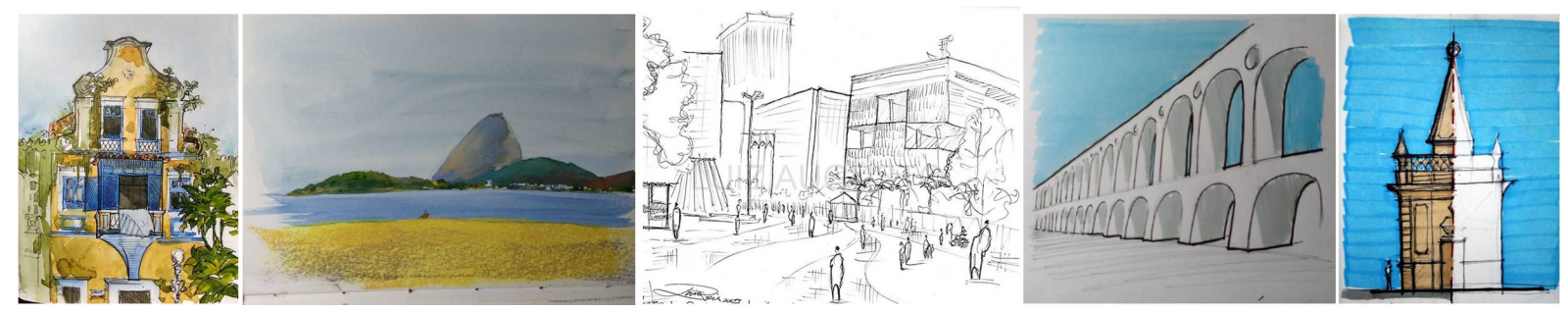

Figuras 1, 2, 3, 4 e 5. Lugares por onde o Rio Carioca passou: Largo do Boticário, Praia do Flamengo, Largo da Carioca, Arcos da Lapa e Praça XV de Novembro. Fonte: Ilustrações dos autores feitas in loco (2016).

\section{A Academia Imperial de Belas Artes e a construção do imaginário nacional}

Há duzentos anos atrás (no ano de 1816), desembarcava na cidade do Rio de Janeiro um grupo de artistas liderados por Joachim Lebreton. 0 grupo que mais tarde foi chamado por Afonso d'Escragnolle

\footnotetext{
${ }^{1}$ Ressalta-se que a elaboração de desenhos in loco é uma metodologia adotada pelo arquiteto e artista plástico Orlando Mollica para facilitar a contato entre o entrevistador e o entrevistado (Nota dos Autores).
} 
Taunay $^{2}$ de Missão Francesa ${ }^{3}$ detinha como objetivo maior a criação de uma Academia de Belas Artes (1826) na então recente capital imperial lusófona ultramarina (Pereira, 2008).

A Academia inaugurou no país o ensino artístico formal que se apoiava nos preceitos gerais do Neoclassicismo: a compreensão da arte como representação do belo ideal; a valorização dos temas nobres, especialmente de caráter exemplar, como a pintura histórica; a importância do desenho como estrutura básica da obra/composição; a preferência por algumas técnicas, como a pintura a óleo, ou de alguns materiais, como o mármore e o bronze, no caso da escultura, entre outros (Pereira, 2008).

Inserida no processo de formação de uma elite intelectual e artística, a Academia Imperial de Belas Artes (AIBA) passou por muitas reformas político-pedagógicas, dentre as quais destacamos a Reforma Pedreira durante a direção de Manuel de Araújo Porto Alegre (1854-1857) que propôs mudanças nos currículos, tais como a inserção da disciplina de história da arte, novas regras para o prêmio de viagem dos estudantes e o ensino dos ofícios (Dias, 2014). Nos seus últimos dias ainda sob a coroa imperial de Dom Pedro II, o ensino da Academia obedecia a um projeto políticopedagógico bem claro e direcionador: criar os fundamentos culturais da Nação e escrever / discutir a história do país de modo a lançar as bases de um verdadeiro Projeto Nacionalista (Pereira, 2008).

A Academia formou gerações de pintores, escultores, arquitetos e outros profissionais ao longo do século XIX, até a sua renomeação para Escola Nacional de Belas Artes com o advento da República (1822) e a partir de 1971 para Escola de Belas Artes da UFRJ.

Um dos muitos consagrados artistas que a Academia formou e, posteriormente, nela exerceu a função de docente, foi o pintor pernambucano Pedro Américo de Figueiredo e Mello, cujo tema de uma de suas obras foi o Rio Carioca representado sob a forma alegórica de um nu feminino idealizado, obra esta inserida no projeto artístico de cunho nacionalista.

\section{Pedro Américo e a obra "A Carioca"}

Na tela "A carioca" (1882) (Figura 6), de autoria de Pedro Américo ${ }^{4}$, alguns dos preceitos formais do Neoclassicismo foram trabalhados, quais sejam: a primazia do desenho - como modo primeiro de estruturação da composição - ao qual se adequa a cor ao desenho, mesmo que a obra revele uma grande riqueza cromática na paisagem que lhe serve de cenário; a centralização da figura humana obedecendo a uma rigorosa distinção entre figura e fundo, evitando qualquer dispersão para além do espaço da representação; adoção de referências clássicas - no caso a posição e forma

${ }^{2} \mathrm{O}$ termo cunhado aparece pela primeira vez no artigo intitulado "A missão artística de 1816 e o meio colonial fluminense", datado de 1911. O cognato "missão" atrela-se à uma ideia civilizatória, de modo a reforçar a intenção de Escragnolle Taunay quanto ao objetivo dos franceses que aqui vieram para impulsionar o progresso científico e artístico na corte de Dom João VI chegada ao Brasil em 1808 (Dias, 2014).

${ }^{3}$ Componentes da Missão francesa: Joachim Lebreton, o líder, Jean Baptiste Debret, pintor histórico, Nicolas-Antoine Taunay, pintor de paisagens e cenas históricas, Auguste Henri Victor Grandjean de Montigny, arquiteto, junto com seus discípulos Charles de Lavasseur e Louis Ueier, Auguste Marie Taunay, escultor, Charles-Simon Pradier, gravador, François Ovide, mecânico, Jean Baptiste Leve, ferreiro, Nicolas Magliori Enout, serralheiro, Pelite e Fabre, peleteiros, Louis Jean Roy e seu filho Hypolite, carpinteiros, François Bonrepos, auxiliar de escultura, e Félix Taunay, filho de Nicolas-Antoine, ainda apenas um jovem aprendiz. Muitos deles trouxeram suas famílias, criados e outros auxiliares. Os pesquisadores acrescentam ainda os nomes de Sigismund Neukomm, músico, e Pierre Dillon, secretário de Lebreton. Seis meses mais tarde, uniram-se ao grupo Marc Ferrez, escultor (tio do fotógrafo Marc Ferrez) e Zéphyrin Ferrez, gravador de medalhas (Pereira, 2008).

${ }^{4}$ Pernambucano nascido no ano de 1843, o jovem Pedro Américo ainda antes de completar dez anos acompanha, como desenhista auxiliar, a expedição científica do naturalista francês Jean Brunet ao Nordeste do Brasil, em 1852. Por volta de 1855, muda-se para o Rio de Janeiro, onde estuda no Colégio Pedro II e no ano seguinte na AIBA. Entre 1859 e 1864, com bolsa concedida pelo imperador D. Pedro II, estuda na École National Superiéure des Beaux-Arts de Paris. Retorna ao Rio de Janeiro em 1864 e assume a cadeira de desenho na AIBA. O novo regime republicano promove, em 1890, uma reforma na AIBA, que passa a chamar-se Escola Nacional de Belas Artes (ENBA). Os professores mais antigos e próximos do imperador são afastados, dentre eles Pedro Américo. Em 1894, Pedro Américo muda-se em definitivo para Florença, na Itália, onde falece em 1905. (Disponível em: www.itaucultural.org.br. Acessado em: agosto de 2016).

(c) Labor \& Engenho, Campinas [SP] Brasil, v.11, n.2, p.116-127, abr./jun. 2017. 
da figura da obra "João Batista criança" (1602) do artista italiano Caravaggio, dentre outros.

Essa obra nos oferece um importante exemplo da incorporação das referências nacionais ao repertório tradicionalmente europeu. Trata-se da alegoria do Rio Carioca por meio de um nu feminino idealizado. Ao tomar como referência o rio que nomeou a população nascida na cidade, Pedro Américo confere e valida a sua importância como elemento definidor da identidade da cidade e de sua população.

\section{0 Rio Carioca}

A cidade do Rio de Janeiro é notoriamente conhecida como uma urbe implantada entre o mar e a montanha. Seu processo de ocupação do solo aconteceu tanto entremeado pelos maciços da Tijuca, Pedra Branca e do Mendanha, quanto delimitado pelas águas da Baía da Guanabara, de Sepetiba e do Oceano Atlântico, con-formando a marca da natureza e da topografia como agentes na construção da paisagem desse lugar.

Nossa reflexão se concentrará no Rio Carioca que nasce na Serra da Carioca, (que juntamente com as Serras dos Três Rios e dos PretosForros compõem o Maciço da Tijuca), mais precisamente nas Paineiras, desce pelas encos-

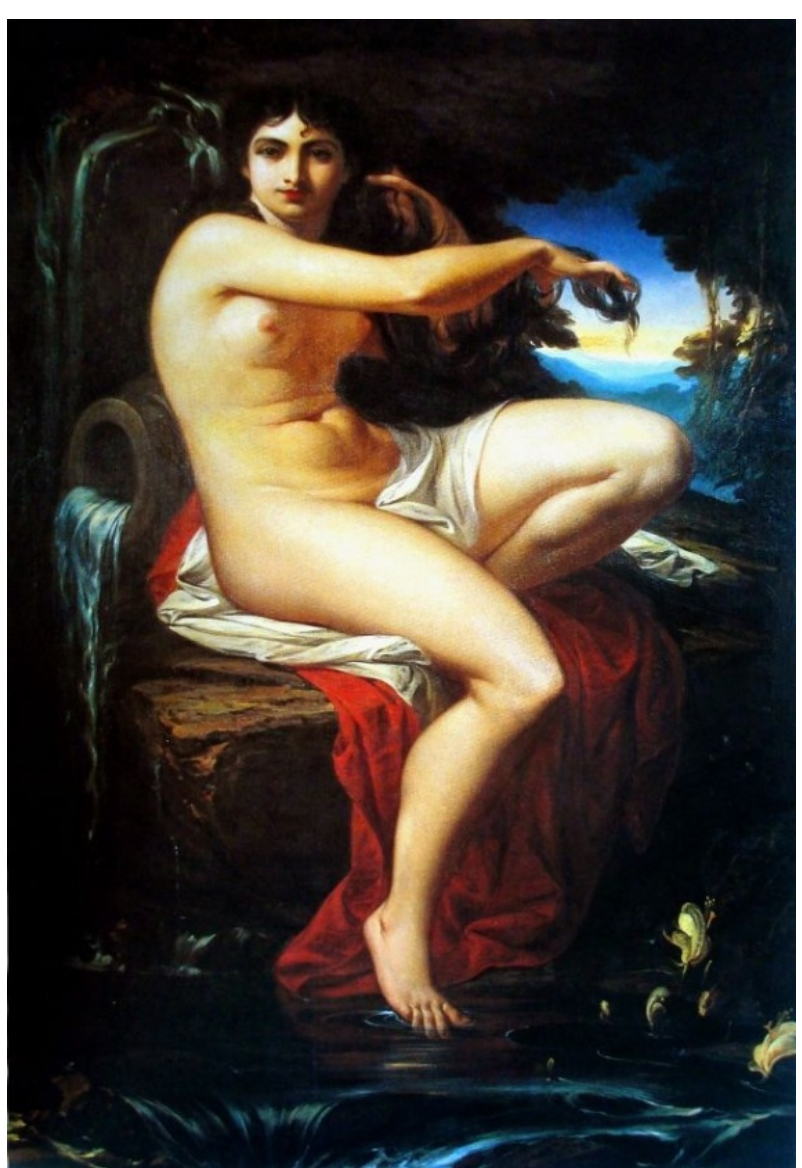

Figura 6. A carioca. (1882). Pedro Américo.Óleo sobre tela. Museu Nacional de Belas Artes, Rio de Janeiro. tas e percorre os vales dos bairros Cosme Velho e Laranjeiras, perfazendo um caminho de $4500 \mathrm{~m}$, alcançando a várzea do Catete, onde no atual Largo do Machado formava uma lagoa. Outra ramificação importante, nos idos tempos, seguia pelas ruas Conde de Baependi e Barão do Flamengo, e no encontro dessas vias formava a ilha da Carioca num delta, que desaguava por fim na Baía de Guanabara (Figura 7).

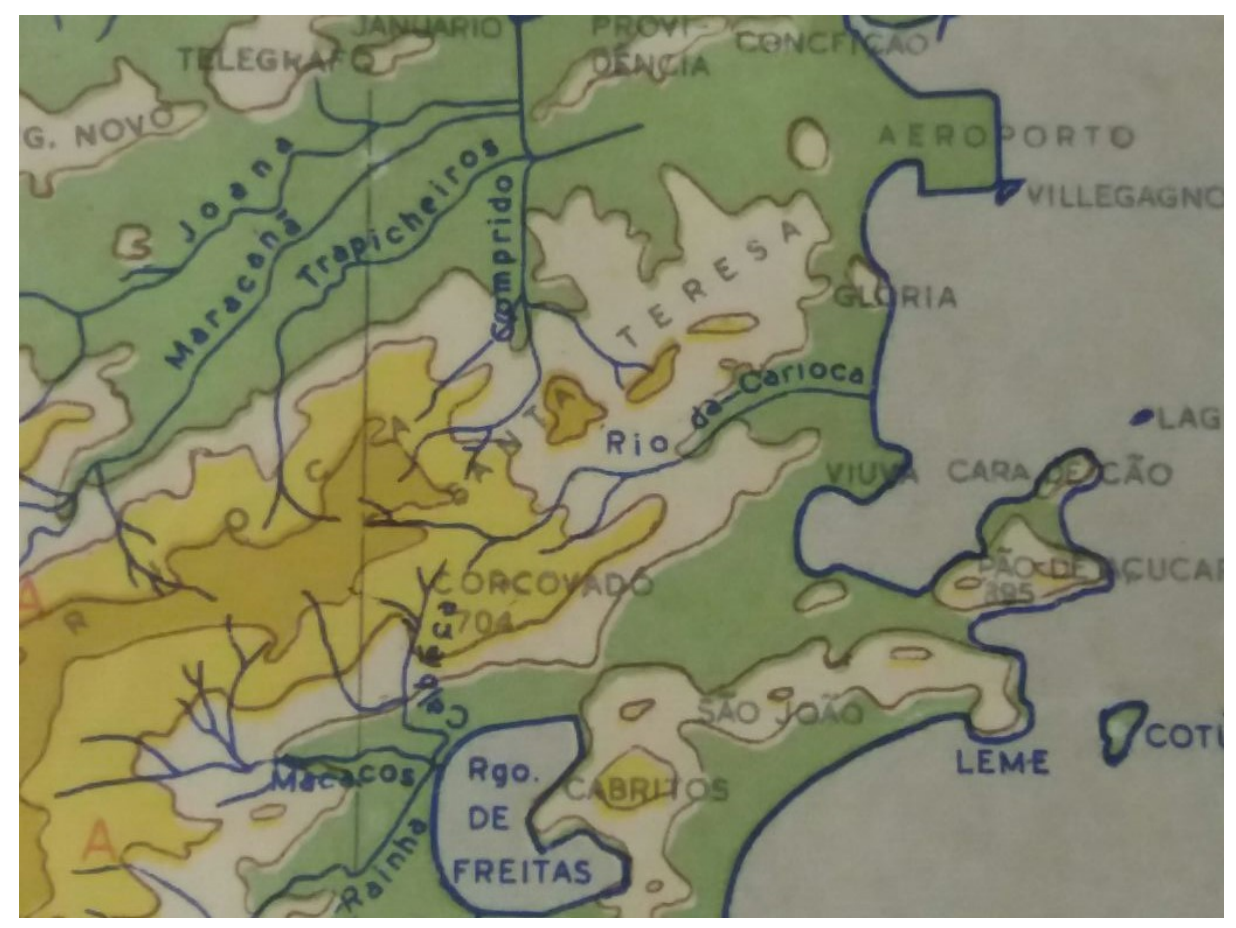

Figura 7. Mapa do Distrito Federal Relevo e Hidrografia.

Fonte: Secretaria Geral de Educação e Cultura, 1946. 
Sobre o delta da Ilha da Carioca havia uma ponte chamada Salema (Figura 8) que dava continuidade ao corredor viário entre o Centro da Cidade à Botafogo e à Cidade Velha implantada na Urca no Morro Cara de Cão.

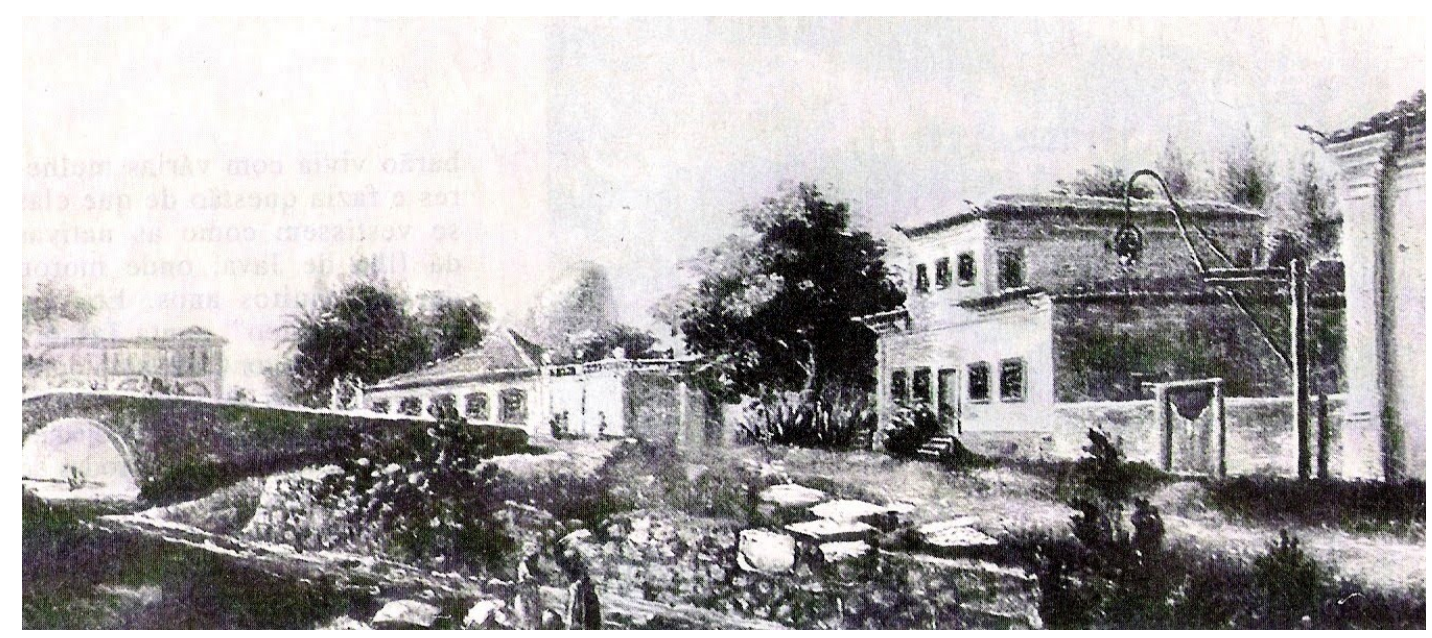

Figura 8. Ponte do Salema. Fonte: http://rionostalgia.blogspot.com.br/2010_03_01_archive.html

O Rio Carioca que além de ter dado o nome aos nativos da cidade do Rio de Janeiro, foi um manancial de água potável para os índios tamoios, que em sua cultura era interpretado como um riacho enfeitiçado por uma Mãe-D'água que vivia em seu leito, tornando-o encantado em virtude da sua água milagrosa responsável pelo embelezamento das mulheres e virilidade dos homens. De grande importância também foi seu uso para os primeiros colonos se fixarem naquela localidade, bem como serviu como fonte de abastecimento de água, implantação de atividades agropastoris e recurso hídrico para os marinheiros e suas mãos. Há registros também do pintor Rugendas, que representou escravas lavadeiras que usavam as águas do Carioca em seus afazeres domésticos (Figura 9).

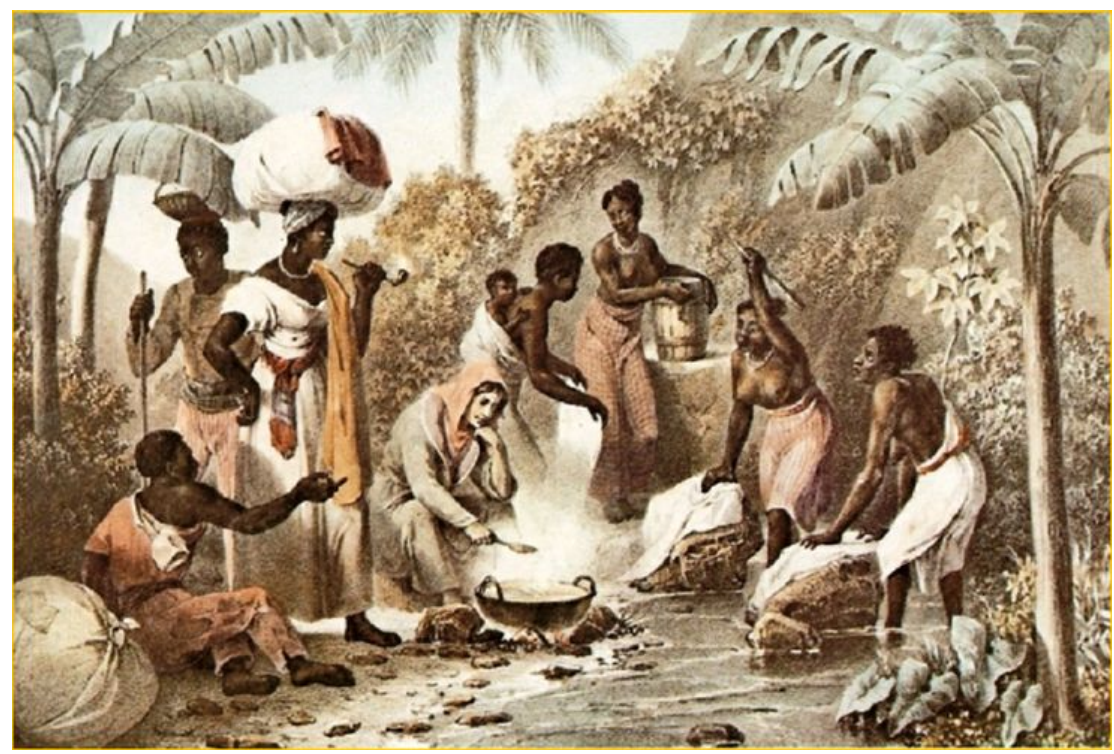

Figura 9. Lavadeiras a beira do Rio Carioca por Rugendas. Fonte: https://br.pinterest.com/pin/404479610263925887/

O Rio Carioca tem a sua nascente na Fonte do Beijo, e em 1672, é proposta a construção de um canal para trazer água ao longo do Morro das Laranjeiras (Figura 10), permeando pelo morro do Desterro, atual Santa Tereza, chegando até a Lagoa do Boqueirão conforme a Carta Régia daquele ano. 

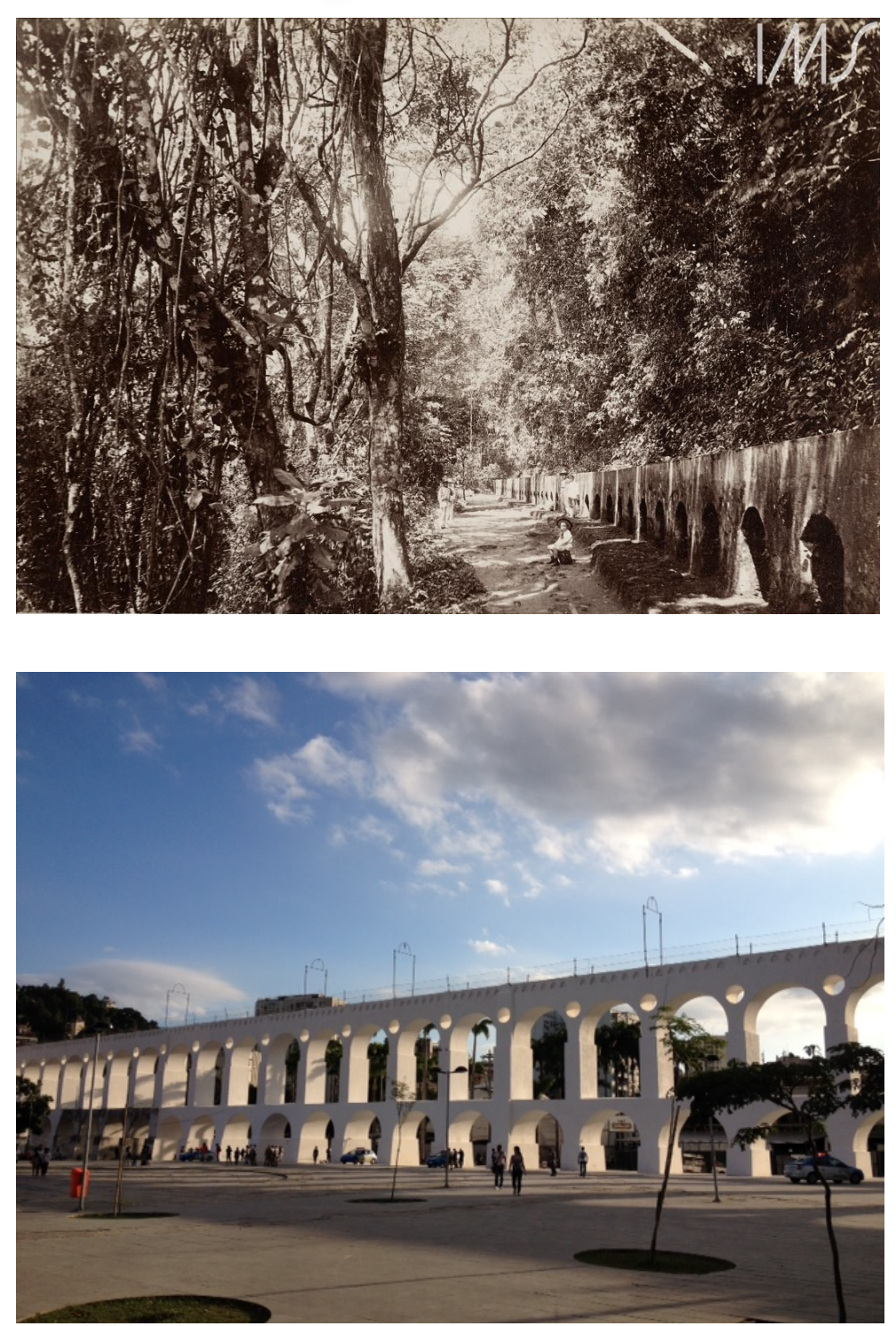

Foi a partir da terceira década do século XVIII, que os governadores programaram o abastecimento para a cidade. Entretanto, no século seguinte, a alternativa de abastecimento de água foi através do Aqueduto da Carioca (Figura 11) chegando até ao Chafariz da Carioca (Figura 12) localizado no Campo de Santo Antônio e, concomitantemente, ao Chafariz da Praça XV (Figura 13).

Figura 10. Aqueduto do Corcovado Fonte: Álbum Viagem pelo Navio Lancaster, Marc Ferrez.
Figura 11. Aqueduto da Carioca,

atualmente conhecido como Arcos da Lapa (2016).

Fonte: Os Autores.

Figura 12. Chafariz da Carioca.

Fonte: https://umpostalpordia.wordpress.com/tag/chafariz-da-carioca/

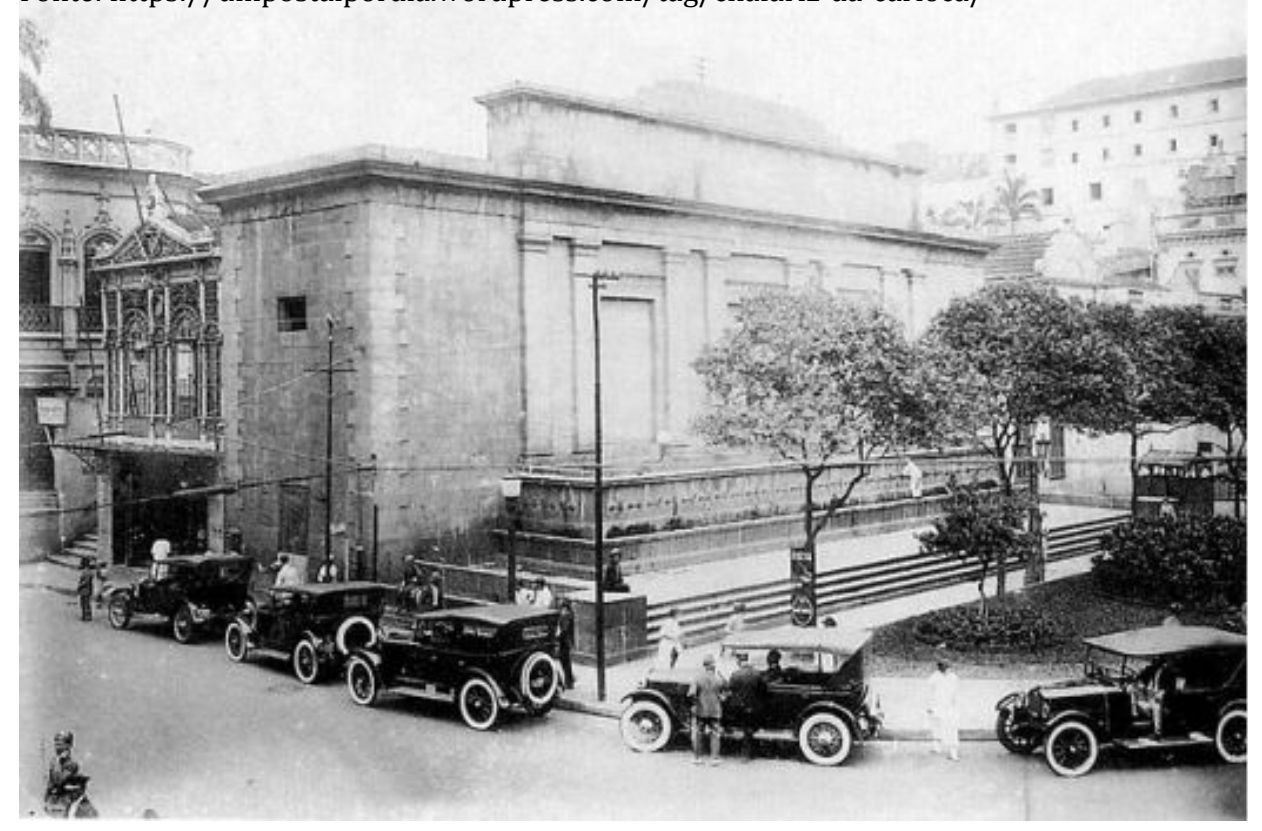




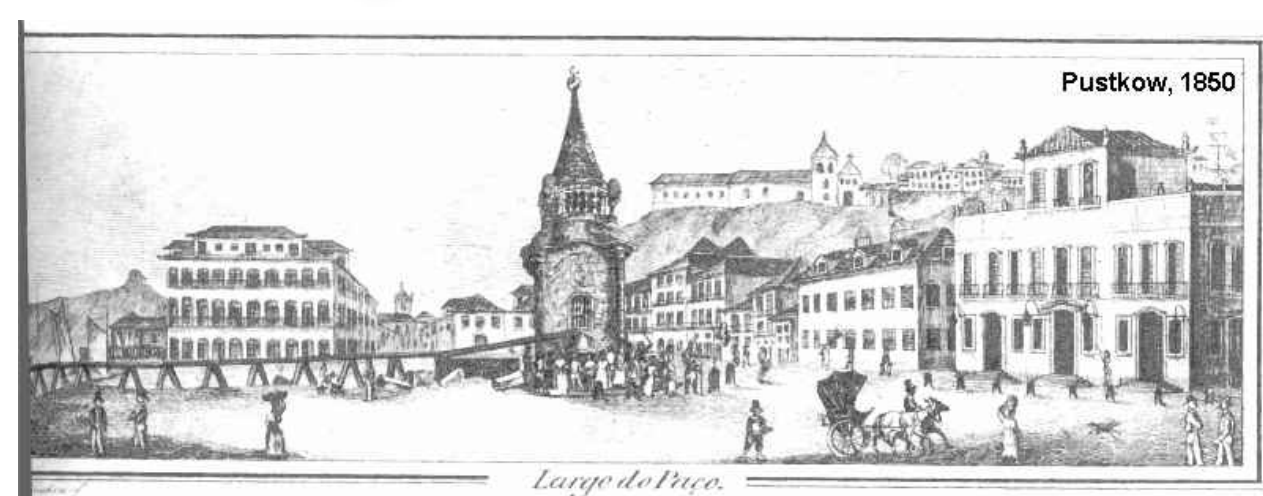

Figura 13. Chafariz da Praça XV.

Fonte: http://ashistoriasdosmonumentosdorio.blogspot.com.br/2010/05/chafariz-da-praca-xv-parte-da-historia.html

Como o manancial era expressivo para aquela época, à medida que a cidade crescia, era possível alimentar outros pontos d'água como o chafariz das Marrecas, a bica da Glória e o Largo do Moura, além da Fonte do Passeio Público (nesse caso por tubulação embutida no solo).

Segundo Correa (1939) o número de pontos de abastecimento de água fez com que houvesse obras de manutenção e do direcionamento de águas de outras fontes para o leito do Rio Carioca. Uma das primeiras providências foi interromper a concessão de terrenos nas margens desse eixo fluvial, evitando assim danos à natureza.

De acordo com Mauricio Abreu (1987), no início do século XIX a chegada da Família Real ao Rio de Janeiro ocasionou um desenvolvimento urbanístico promissor na cidade. 0 vetor de expansão naquela época era o Largo do Machado, pois alguns membros da Corte assentavam suas propriedades naquela localidade, valorizando substancialmente essa área. Importante ressaltar que nessa mesma época, o traçado do Rio Carioca, desde a sua encosta até a planície, tornou-se também um marco de expansão da urbe à medida que dezenas de chácaras foram implantadas ocupando quase a totalidade do vale, bem como a instalação da Fábrica de Tecidos Aliança e sua vila operária no final do novecentos, impulsionando novos dimensionamentos a vida urbana do bairro.

Com a Reforma de Pereira Passos no início do século XX, imbuída pelo viés da Modernidade, houve o alargamento das ruas no vale do Cosme Velho e Laranjeiras bem como uma tentativa de dominar a natureza, canalizando o Rio Carioca (Figura 14). Associado a isso a verticalização da arquitetura a partir da década de 1930, estimulou uma densidade no âmbito urbanístico promovendo uma transformação da paisagem ocasionando, principalmente, o início do desaparecimento do traçado do Rio Carioca naquele lugar.

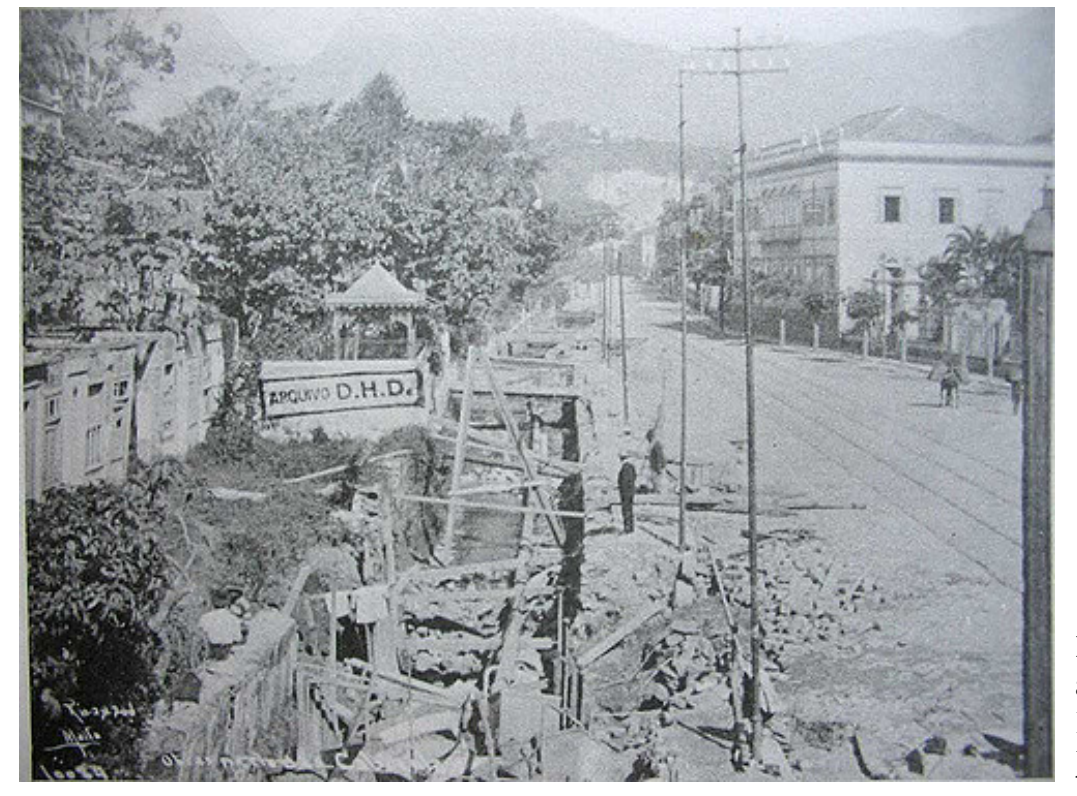

Figura 14. Canalização do Rio Carioca ao longo da Rua das Laranjeiras. Fonte: Augusto César Malta in O Rio de Janeiro de Lima Barreto Volume II. 


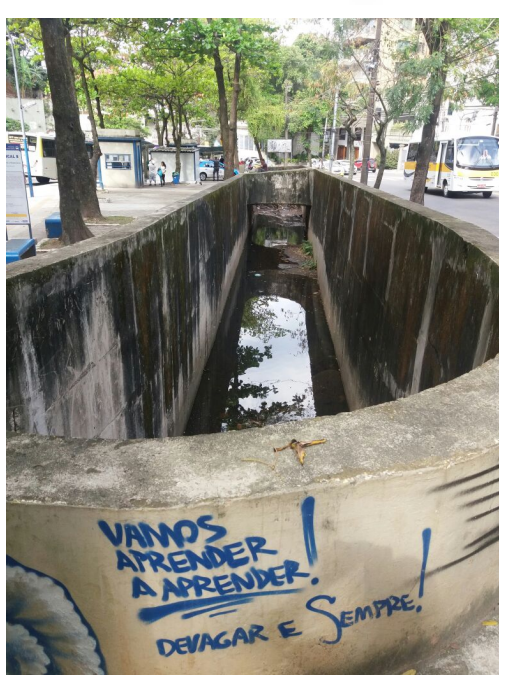

Atualmente, o Rio Carioca mostra-se descoberto e extremamente maltratado (sedimentos, lixos e visivelmente poluído) em trechos do bairro do Cosme Velho (Figura 15): na rua do mesmo nome, demarcando a entrada do Largo do Boticário, junto a um terminal de ônibus, segue canalizado sob as ruas do bairro contíguo denominado Laranjeiras, desembocando na Estação de Tratamento de Água do Aterro do Flamengo, através de um enrocamento artificial no intuito de despoluí-lo junto à Baía de Guanabara.

Figura 15. Rio Carioca no Cosme Velho, um dos poucos trechos existentes a céu aberto (2016).

Fonte: Os Autores.

\section{Investigando os resquícios de um rio}

As questões elaboradas tiveram o objetivo de identificar quais são os rios da cidade do Rio de Janeiro que ainda estão na memória da população, e se especificamente, o Rio Carioca está entre eles, uma vez que a maior parte dos rios desta cidade foram canalizados ou escondidos em galerias subterrâneas. Tendo uma resposta afirmativa com relação as duas abordagens iniciais, a entrevista foi direcionada para o conhecimento do entrevistado sobre o percurso principal e secundário do Rio Carioca por meio de fotografias dos seguintes locais: Largo do Boticário, Praça José de Alencar, Praia do Flamengo (em frente a rua Barão do Flamengo), Arcos da Lapa e Chafariz da Praça XV de Novembro. No caso de uma resposta negativa sobre as primeiras perguntas, buscou-se identificar se os entrevistados que não conhecem o Rio Carioca conseguem identificar na paisagem se existe algum resquício por onde passou um curso d'água. Com esta última pergunta, procurou-se verificar se a história da paisagem ainda pode ser identificada nos monumentos ou edifícios da cidade. Por fim, foi perguntado o gênero, a idade, o grau de instrução e se é morador da cidade do Rio de Janeiro para que seja possível traçar o perfil da população que conhece e que não conhece o Rio Carioca.

\subsection{Resultado das Entrevistas}

Do universo de pessoas entrevistadas em cada trecho por onde o Rio Passa ou passava na cidade, ficou evidenciado que 70\% não elegeram o Rio Carioca como importante, pois foram citados os rios que hoje encontram-se canalizados, e estão a céu aberto como por exemplo: o Rio Maracanã na Tijuca, Canal do Mangue na Av. Francisco Bicalho, Rio Grande em Jacarepaguá e também outros rios que não estão dentro da cidade do Rio de Janeiro.

Quando questionamos se conhece especificamente o Rio Carioca, os entrevistados que citaram outros rios, não detinham na memória o rio que estamos investigando, sendo que esse perfil de entrevistados eram na maioria do gênero masculino entre 30 e 50 anos e moradores da cidade.

Os 30\% dos entrevistados que disseram conhecer o Rio Carioca não tinham conhecimento que o rio foi desviado e que passava por diferentes pontos da cidade. 0 percurso conhecido pela maioria era os Arcos da Lapa. Pode-se identificar que o perfil destas pessoas tem idade acima de 51 anos e nível superior completo. Ao apresentar imagens do Largo do Boticário, da Praça José de Alencar, da Praia do Flamengo, dos Arcos da Lapa e da Praça XV de Novembro e perguntar por quais destes locais o Rio Carioca passava, a resposta da maioria foi Arcos da Lapa e em seguida Largo do Boticário e, por último, Praça XV de Novembro. Isso demonstra que a memória do Rio Carioca está vinculada a espaços que evidenciam um patrimônio edificado, uma vez que os locais citados apresentam um conjunto de edificações históricas.

O resultado da quinta e última pergunta será apresentado em conjunto com outros resultados e descrição particular de cada local. 


\subsubsection{Largo do Boticário}

O Beco e o Largo do Boticário5 (Figura 16) compõem um conjunto arquitetônico cujo tombamento inclui interiores, elementos arquitetônicos, artísticos e decorativos, pavimentação, aspectos urbanísticos e paisagísticos. As casas eram originalmente térreas e foram construídas no final do século XVIII. Na primeira metade do século XIX as edificações foram reformadas incorporando elementos do Neocolonial incentivadas pela onda Nacionalista dos anos 1920. Em algumas edificações, foram utilizados materiais oriundos de imóveis históricos demolidos quando da abertura da Avenida Presidente Vargas. Dentre os profissionais que projetaram / reformaram as casas figuram Lúcio Costa, Warchavchik e o diplomata Rodolpho Siqueira que era arquiteto amador (Czajkowski, 2000; PCRJ, 2008).

Entre os entrevistados deste local, 70\% eram moradores do bairro do Cosme Velho e o restante turistas. Todos os moradores sabiam o nome do rio, mas nem todos sabiam que ele passava por outros trechos da cidade. Já todos os turistas sabiam que o Rio Carioca passava pelos Arcos da Lapa, local que ainda iriam visitar.

Nesse local de entrevistas, cabe ressaltar que a quinta pergunta torna-se evidente, pois o corpo d'água está canalizado e não subterrâneo. Foram identificados por dois moradores elementos que um dia fizeram parte do cotidiano dos moradores locais, como a escada de acesso aos lotes pelo rio (Figura 17) e o local onde havia uma fonte de água construída na metade do século XIX.

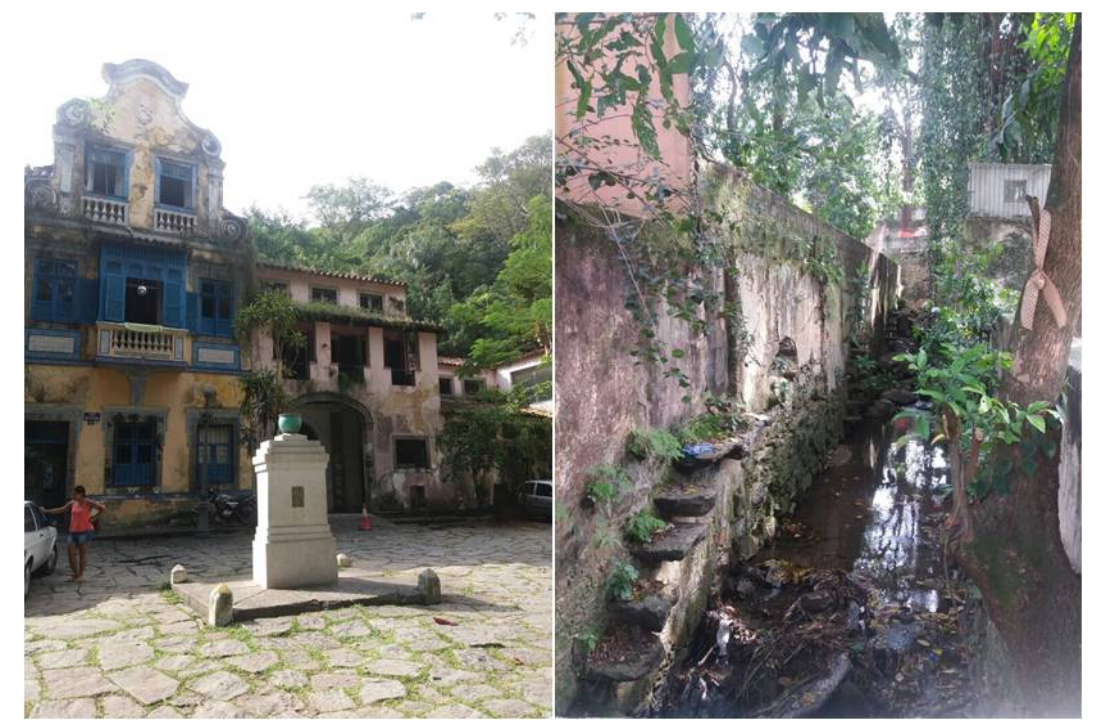

Figuras 16 e 17. Largo do Boticário e trecho do Rio Carioca (2016).

Fonte: Os Autores.

\subsubsection{Praia do Flamengo}

No início do século XX foi aberta a Av. Beira Mar que passava pelo bairro do Flamengo ligando o centro a Botafogo. Na década de 50 do mesmo século foi feito um aterro, resultante do desmonte do Morro do Castelo no centro da cidade, devido a necessidade de se abrir novas vias em direção a zona sul. 0 Aterro do Flamengo é um parque urbano, onde está a praia do Flamengo, que possui principalmente equipamentos de lazer como: museus, casas de show, quadras para diferentes esportes, restaurante, quiosques, áreas de brinquedo infantil, pista de skate (Abreu, 1987).

As entrevistas neste local foram feitas no Aterro do Flamengo, em frente a Rua Barão do Flamengo, onde o Rio Carioca passa atualmente dentro de galeria subterrânea e deságua no mar passando por uma UTR (Unidade de Tratamento de Rio - denominada Carioca). A metade dos entrevistados eram moradores do bairro do Flamengo, possuíam entre 30 e 50 anos e disseram

50 conjunto arquitetônico, paisagístico e urbanístico do Beco e Largo do Boticário são objeto de tombamento estadual em 12/09/1990 pela Resolução SEC 26 de 31/08/1990 (PCRJ, 2008, p.122). 
que conhecem o Rio Carioca. Elas identificam o Largo do Boticário e a Praia do Flamengo como o único percurso do Rio Carioca. Também identificaram o deck por onde caminham pela manhã como sendo parte do Rio. A outra metade dos entrevistados não conhecia o Rio Carioca e não identificaram o deck como sendo o esgoto tratado e laçado no mar. Vale ressaltar que o perfil destes entrevistados possuía abaixo de 30 anos na maioria e com ensino médio completo.

\subsubsection{Praça José de Alencar}

Localizada no bairro do Flamengo, a praça se configura atualmente apenas como uma rótula de circulação de veículos (Figura 18) encimada por um grande conjunto escultórico em homenagem ao escritor brasileiro José de Alencar (Figura 19). 0 monumento ${ }^{6}$ foi modelado e fundido pelo escultor Rodolfo Bernardelli, tendo sido inaugurada em 1897. Em seu pedestal há os baixosrelevos representando cenas dos romances do escritor: "O Guarany", "O gaúcho", "O sertanejo" e "Iracema" (PCRJ, 2008).

Neste local as entrevistas foram feitas na maior parte com mulheres que possuíam idade entre 30 e 50 anos e não residentes da região. Pode-se identificar que a maioria não conhece o Rio Carioca, e na paisagem não conseguiram apontar nada que lembrasse um corpo d'água, ficando curiosas a respeito do assunto. Elas destacaram o monumento ao José de Alencar com um símbolo do local, embora não sabiam quem foi o escritor.

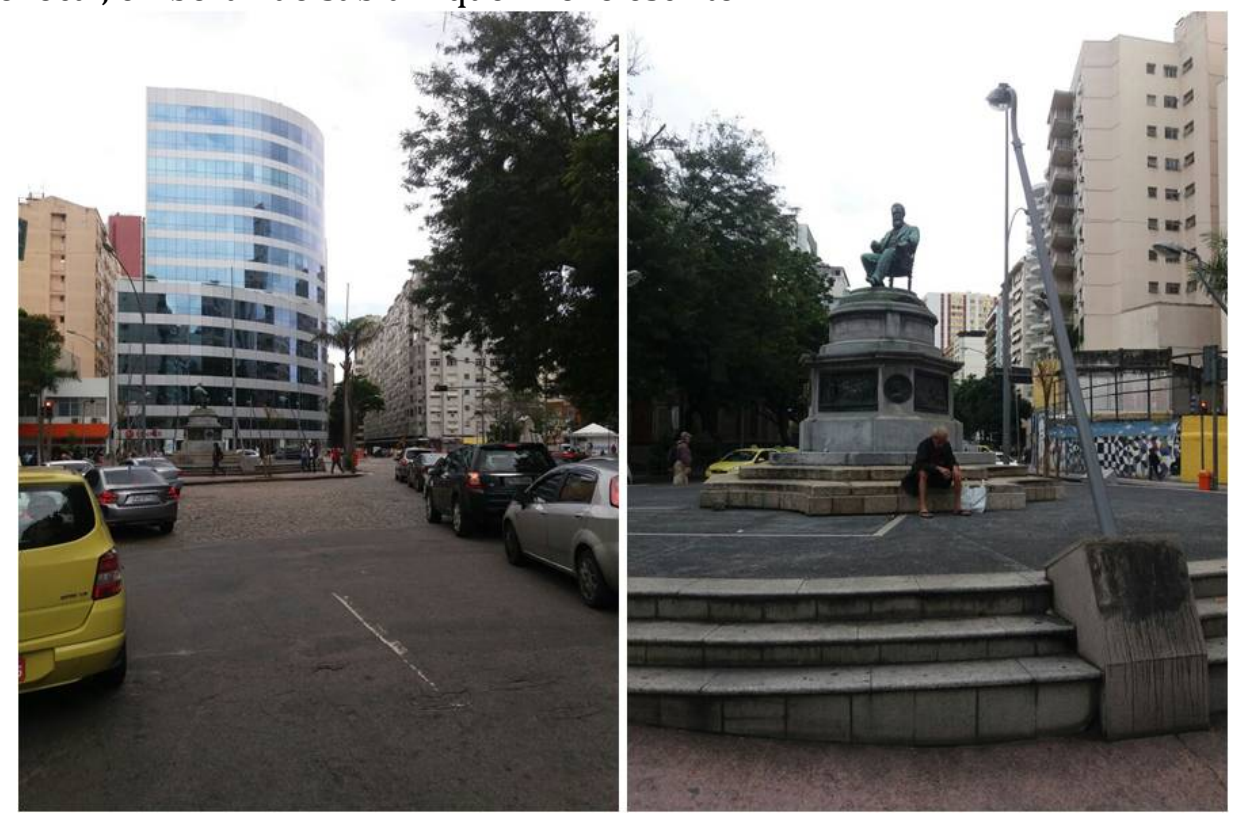

Figuras 18 e 19. Praça José de Alencar (2016). Fonte: Os Autores.

\subsubsection{Arcos da Lapa}

Para abastecer a cidade, em 1726, o rio carioca foi canalizado através de um aqueduto (Arcos da Lapa) até o chafariz do Largo da Carioca que possuía diversas ramificações. Construído em alvenaria, o aqueduto da Lapa foi concluído em 1750 pelo Brigadeiro Alpoim. 0 monumento apresenta 2 (duas) fileiras superpostas de arcos plenos (Czajkowski, 2000; PCRJ, 2008).

Em 1896, os arcos foram convertidos em via para a passagem dos bondes para a ligação do bairro de Santa Teresa ao centro da cidade, época esta quando foi acrescido um parapeito de alvenaria com pequenos arcos ogivais. Na década de 1960, o casario que se apoiava nos arcos foi demolido. Nessa mesma época foram fechados os arcos ogivais com vistas à recuperação da imagem colonial do monumento (Czajkowski, 2000; PCRJ, 2008).

\footnotetext{
${ }^{6} \mathrm{O}$ conjunto escultórico é um bem tombado a nível estadual pelo Decreto Estadual 25.693 de 23/08/2005 (PCRJ, 2008, p.53).
} 
Os entrevistados neste local tinham a idade compreendida entre 30 (trinta) e 50 (cinquenta) anos e moradores da cidade, no entanto nenhum deles conhecia o Rio Carioca, mas a maior parte identificou o monumento dos Arcos como sendo um possível local por onde o Rio passava e que ao mesmo tempo valoriza a cidade.

\subsubsection{Chafariz do Mestre Valentim — Praça XV}

0 chafariz $^{7}$ atual foi construído em 1789 por Mestre Valentim para a remodelação do cais para o porto do terreiro da Igreja do Carmo no século XVIII (Czajkowski, 2000; PCRJ, 2008).

O chafariz, de influência estilística Maneirista e Barroca, apresenta a forma de uma torre de 4 (quatro) faces com ornamentos em pedra-de-lióz sobre a qual assenta-se uma pirâmide que originalmente trazia no ápice as armas portuguesas e que em 1842 foram substituídas por uma esfera encimada pela Coroa Imperial. A água saía de 3 (três) corunchéis nas laterais e tinha mais 2 (duas) torneiras no cais para abastecer as embarcações (Czajkowski, 2000; PCRJ, 2008).

Pela escada lateral do chafariz a família Real Portuguesa desembarcou no dia 8 de março de 1808. Desta mesma escada, D. João VI voltou para Portugal em 26 de abril de 1821, assim como seu filho, D. Pedro I, em 7 de abril de 1831. Após a proclamação da república, a família real voltou para Portugal na madrugada de 17 de novembro de 1889, após dois dias de prisão domiciliar, e passou por essa mesma escada (Czajkowski, 2000; PCRJ, 2008).

Em 1990, trechos das escadarias foram resgatados através de estudos arqueológicos. No ano de 2016, o viaduto da perimetral, que passava entre o chafariz e a baía, foi demolido.

As entrevistas na Praça XVI de Novembro foram feitas com pessoas que na maioria moram na cidade de Niterói e possuem faixa etária variada. Apenas $25 \%$ das pessoas entrevistadas disseram conhecer o Rio Carioca. As outras $75 \%$ não conheciam o Rio Carioca, mas mais de $50 \%$ delas identificaram o Chafariz do Mestre Valentim como um local que possivelmente passava água e que valoriza a paisagem.

\section{Considerações finais}

Esta pesquisa teve como objetivo principal a reflexão sobre a relação entre o Rio Carioca, a cidade do Rio de Janeiro e o seu reconhecimento junto à população da cidade em termos de memória e identidade. Como roteiro metodológico, traçamos breves linhas acerca do projeto político-pedagógico do ideário nacionalista promovido pela antiga Academia Imperial de Belas Artes do Rio de Janeiro no século XIX, cujo ponto de partida foi a obra "A carioca", retrato idealizado de cunho identitário nacionalista do Rio Carioca de autoria do artista Pedro Américo. Logo após, apresentamos um breve histórico do Rio Carioca, destacando seu trajeto original e atual. Identificamos e elegemos 5 (cinco) lugares em seu percurso, e nestes aplicamos um questionário estruturado para que pudéssemos verificar o objetivo proposto.

Por uma primeira abordagem do tema, podemos concluir com as entrevistas que a memória e a identidade do Rio Carioca encontram-se atualmente muito fragilizadas. A investigação mostrou que as pessoas entre 30 e 50 anos, que foram a maioria dos entrevistados, não possuem qualquer lembrança sobre o Rio Carioca. Podemos afirmar que o perfil de pessoas que possuem idade acima de 50 anos foram as que mais tinham informações sobre o percurso do Rio. Deste universo, dos cinco locais por onde o Rio Carioca fluiu, apenas 2 (dois) lugares ainda possuem trechos visíveis do rio, o que gera, provavelmente, um conhecimento expressivo acerca de sua existência. Nesses locais, cerca de $70 \%$ e $50 \%$ dos entrevistados do Largo do Boticário e da Praia do Flamengo, respectivamente, conhecem o Rio Carioca. Nestes trechos, identificamos ainda placas informativas sobre o nome do rio. Dos demais locais por onde o Rio Carioca percorria, apenas 1 (um), a Praça XV, um de seus locais de deságue, cerca de 25\% dos informantes afirmaram que o conheciam, nos demais, nenhum entrevistado relatou essa afirmação. Podemos

\footnotetext{
${ }^{7} \mathrm{O}$ chafariz foi tombado a nível federal em 11/05/1938 tendo sido inscrito no Livro Histórico, vol.1, inscrição 25 e no Livro de Belas-Artes, vol.1, inscrição 58 (PCRJ, 2008, p.66).
} 
fazer assim um paralelo entre a visibilidade e a informação do Rio Carioca com o reconhecimento que a população tem a seu respeito, aspectos esses que poderiam ser usados futuramente de modo a propiciar um resgate da memória do Rio Carioca e sua valorização e identificação com a cidade do Rio de Janeiro e população conforme a imagem proposta na obra de Pedro Américo.

\section{Referências}

Abreu, M. (1987). Evolução Urbana do Rio de Janeiro. Rio de Janeiro: IPLANRIO, Zahar.

Albarello, L. et al. (1997). Práticas e métodos de investigação em Ciências Sociais. Lisboa: Gravida.

Correa, A. M. (1939). Terra Carioca - Fontes e Chafarizes. Rio de Janeiro: Imprensa Nacional.

Cosgrove, D. (1998). A geografia está em toda parte: cultura e simbolismo nas paisagens humanas. In R. L. Corrêa, \& Z. Rosendahl (Orgs.). Paisagem, tempo e cultura (pp. 92-123). Rio de Janeiro: EdUERJ.

Czajkowski (org.) (2000). Guia da Arquitetura colonial, Neoclássica e Romântica do Rio de Janeiro (p. 61).

Freire, D., \& Pereira, L. L (2002). Historia Oral, Memoria e Turismo Cultural. In S. M. Murta, \& C. Albano (Orgs.). Interpretar o Patrimônio: um exercício do olhar (pp.121-130). Belo Horizonte: Ed. UFMG, Território Brasilis.

Prefeitura da Cidade do Rio de Janeiro (2008). Guia do Patrimônio Cultural Carioca. Bens tombados 2008 (4a. ed. Revisada, 268 p.il.). Rio de Janeiro: Secretaria Extraordinária do Patrimônio Cultural.

Dias, E. (2014). Arte e Academia: entre política e natureza (1816 a 1857). In BARCINSKI, F. W. Barcinski (Org.). Sobre a arte brasileira: da Pré-história aos anos 1960 (pp. 136-173). São Paulo: Editora WMF Martins Fontes: Edições SESC São Paulo.

Pereira, S. G. (2008). A arte no Brasil no século XIX e início do XX. In M. A. R. de Oliveira, S. G. Pereira, \& A. A. da Luz. História do Brasil: textos de síntese (pp.58-98) (Série Didáticos). Rio de Janeiro: Editora UFRJ.

Ruquoy, D. (1997). Situação de entrevista e estratégia do entrevistador. In L. Albarello et al.. Práticas e métodos de investigação em Ciências Sociais (pp.84-116). Lisboa: Gravida.

Vianna, H. (1993). Vale das Laranjeiras - Cosme Velho: Um Recanto da Mata Atlântica. Rio de Janeiro: PCRJ/SMC/DGPC. 